\title{
Massive/Small Open Online Courses (MOOC/ SOOC) e Recursos Educacionais Abertos (REA): inovação disruptiva na educação online e aberta
}

Massive / Small Open Online Courses (MOOC / SOOC) and Open Educational Resources (OER): disruptive innovation in online and open education

Massive / Small Open Online Courses (MOOC / SOOC) y Recursos Educativos Abiertos (REA): innovación disruptiva en la educación en línea y abierta

\section{Elena Maria Mallmann*}

\section{Resumo}

O foco é o potencial dos Massive/Small Open Online Courses (MOOC/SOOC) e Recursos Educacionais Abertos (REA) para inovação disruptiva na educação online e aberta. Os fundamentos teóricos são os princípios da inovação e a prática das cinco liberdades (reter, reutilizar, readaptar, remixar, redistribuir) no contexto da Web 2.0. Os procedimentos metodológicos do Design-Based Research (DBR) contemplaram análise exploratória e triangulação

EMM: Doutora em Educação, e-mail: elena.ufsm@gmail.com 
de dados em ciclos iterativos de planejamento, implementação, avaliação para o redesign no cenário de um SOOC. Os resultados mostram que o trabalho emergente de (co)autoria, como prática das cinco liberdades do conteúdo aberto, incentiva inovação educacional disruptiva quando: a) as situações de aprendizagem flexibilizam processos tradicionais nas universidades; b) recursos e atividades são disponibilizadas com licenças permissivas gerando reutilização, reformulação e recompartilhamento com foco na transformação das práticas cotidianas; c) pode-se encorajar o aprimoramento de Fluência Tecnológico-Pedagógica (FTP); d) expande-se compreensões e percepções dos participantes sobre si mesmos e sobre os demais atores acerca de como as decisões e práticas cotidianas, mediadas pelas tecnologias em rede no contexto da Web 2.0, podem impactar o mundo real e o curso das vidas.

Palavras-chave: Recursos Educacionais Abertos. Tecnologia Educacional. Educação Aberta.

\section{Abstract}

The focus is the potential of the Massive / Small Open Online Courses (MOOC / SOOC) and Open Educational Resources (OER) for disruptive innovation in online and open education. The principles of innovation and practice of the five freedoms (retaining, reusing, re-adapting, remixing, redistributing) in the context of Web 2.0 base this analysis theoretically. The Design-Based Research (DBR) methodological procedures included exploratory analysis and triangulation of data sources in iterative cycles of planning, implementation, and evaluation for redesign in the SOOC scenario. The results show that the emergence of (co) authorship as a practice of the five freedoms of open content encourages disruptive educational innovation when: a) learning situations make learning processes more flexible in universities; b) resources and activities are made available with permissive licenses allowing reuse, reformulation and re-sharing with a focus on the transformation of daily practices; c) the improvement of Technological-Pedagogical Fluency (FTP) can be encouraged; d) participants' understandings and perceptions, about themselves and other stakeholders, about how the day-to-day decisions and practices, mediated through network technologies in the context of Web 2.0, can impact real worlds and the course of lives.

Keywords: Open Educational Resources. Educational Technology. Open Education. 


\section{Resumen}

El enfoque es el potencial de los Massive/Small Open Online Courses (MOOC/SOOC) e Recursos Educativos Abiertos (REA) para la innovación en la educación en línea y abierta. Se fundamenta teóricamente en los principios de la innovación y la práctica de las cinco libertades (retener, reutilizar, readaptar, redimir, redistribuir) en el contexto de la Web 2.0. Los procedimientos metodológicos de diseño-basado en investigación (DBR) contemplaron análisis exploratorios y triangulación de fuentes de datos en ciclos iterativos de planificación, implementación, evaluación para el reajuste en el escenario de un SOOC. Los resultados muestran que el trabajo emergente de co-autoría, como práctica de las cinco libertades del contenido abierto, incentiva innovación educativa disruptiva cuando: a) las situaciones de aprendizaje flexibilizan procesos tradicionales en las universidades; b) recursos y actividades están disponibles con licencias permisivas permitiendo reutilización, reformulación y recompartición con foco en la transformación de las prácticas cotidianas; c) se puede alentar el perfeccionamiento de la Fluencia Tecnológica-Pedagógica (FTP); d) se expande la comprensión y percepción de los participantes acerca de sí mismos y sobre los demás actores involucrados acerca de cómo las decisiones y prácticas cotidianas mediadas por las tecnologías en red en el contexto de la Web 2.0 pueden impactar sobre los mundos reales y el curso de las vidas.

Palabras clave: Recursos Educativos Abiertos. Tecnología Educativa. Educación abierta.

\section{Introdução}

A produção educacional colaborativa, livre e aberta no contexto da Web 2.0 (O'REILLY, 2005; BRUNS, 2008; BONK, 2009) requer atenção às alternâncias incisivas mobilizadas pelos atos ético (ato responsável e que responde sobre algo a alguém) e estético (criação) (JACQUES, 2017). No escopo das controvérsias e dos cruzamentos, a educação online e aberta pode convergir com os princípios da cultura REA, dos Massive/Small Open Online Courses (MOOC e SOOC), do movimento internacional do 
software livre e das práticas científicas abertas. O foco analítico nesse artigo concentra-se na integração de Recursos Educacionais Abertos (REA) no design pedagógico (FREEMAN, 2005) de cursos abertos na universidade gerando inovação disruptiva (CHRISTENSEN; RAYNOR; MCDONALD, 2015) na educação online e aberta.

\section{Inovação educacional disruptiva no contexto da Web 2.0}

Um dos principais questionamentos aos conteúdos livres e abertos disponibilizados em plataformas online, como a Wikipédia, por exemplo, é a respeito da qualidade (PESTANA; CARDOSO, 2017). A variação e a necessidade de verificação da qualidade dos REA e dos MOOC/SOOC são apontadas como uma de suas desvantagens. Trata-se de um aspecto polêmico e questionável, uma vez que grande parte das pessoas que problematizam e colocam os REA e, de modo geral, a educação online e aberta em xeque, muitas vezes deixam de analisar criticamente seus preceitos, políticas, infraestrutura, sistemas e dinâmicas de funcionamento. O eixo sempre gira em torno da "duvidosa qualidade" com a velha hipótese de que a contribuição de qualquer pessoa na geração de conteúdos declina a veracidade (BRUNS, 2008). Windle e outros (2010, p. 14) apostam que "uma ênfase na garantia de qualidade pode ser um motor de compartilhamento e reutilização, e os elementos que permitem um bom design para a usabilidade também parecem promover a reutilização".

Muitos professores não credibilizam a Wikipédia como fonte confiável de pesquisa (PESTANA; CARDOSO, 2017). Enquanto isso, preferem que os estudantes utilizem como fontes de pesquisa materiais produzidos por editoras pertencentes à determinados grupos políticos e mantenedores dos produtos culturais em circulação em determinados países. Destarte, ao duvidar da qualidade de conteúdos online e abertos pode-se mesmo concluir que todo conteúdo impresso e a educação face-to-face é legítima, verídica, imparcial e inquestionável? O risco de desvirtuar o foco dos necessários pontos de estudo e pesquisa para aspectos 
secundários, parece estar concentrado em toda e qualquer forma de generalização ausente de indicadores e matrizes teórico-práticas sensíveis à constante problematização.

A Internet e suas variadas tecnologias podem ser consideradas instrumentos contemporâneos poderosos para promover a democracia e inovação (CASTELLS, 2003). “O verdadeiro valor está na organização de redes de inovação livremente agregadas para capturar a casualidade e a diversidade de inovações e progressos científicos. Redes de capital humano flexíveis e distribuídas" (TAPSCOTT; WILLIAMS, 2007, p. 143). Portais públicos podem empoderar a população gerando mais condições de cidadania com acesso a muitos materiais, documentos, processos e projetos, inclusive, prevendo canais de interação e atualização de feedbacks. Zanin (2017) explica que há duas limitações em relação ao problema da falta de clareza nos portais quanto aos direitos autorais, propriedade intelectual e licenciamento: "inadequação da legislação que trata dos direitos autorais, que não evoluiu na mesma velocidade que a sociedade da informação; falta de informação nos repositórios que disponibilizam material "aberto" a respeito desses direitos" (p. 21). A autora sugere uma lista de itens que precisam ser melhor observados em sites, repositórios e portais como: "definição de direitos autorais; definição e citação dos direitos morais; definição e citação dos direitos patrimoniais; tipo de licença utilizada nos recursos; usos permitidos; usos proibidos e citação da legislação aplicável" (ZANIN, 2017, p. 21).

O conceito de livre acesso à informação e à literatura acadêmica é a base para a criação do projeto Science Commons ${ }^{1}$. O propósito é remover barreiras legais e técnicas para incentivar a inovação e a colaboração científica entre cientistas. Com liberdades asseguradas para acessar, retrabalhar e compartilhar os dados é possível integrar resultados de pesquisa de diversas formas beneficiando o desenvolvimento científico-tecnológico (ARAYA; VIDOTTI, 2010). Portanto, nesse cenário de abertura e prática da liberdade, práticas educacionais abertas, REA e outros movimentos de

1 Cf. <http://sciencecommons.org/about/>. 
democratização via educação online não se limitam à valores altruístas, filantrópicos e de voluntariado. Na verdade, implicam precisas análises epistemológicas, econômicas e de impactos socioculturais na produção, participação e democratização do acesso global ao conhecimento. O que inegavelmente inclui a justiça social, qualidade de vida e bem-estar alavancando movimentos inéditos de inovação disruptiva. Mota e Scott (2014, p. 51) dizem que a inovação tem as seguintes características:

é fruto da intencional flexibilidade temporária de regras, normas e de arranjos tradicionais dos recursos de tal maneira a explorar possibilidades alternativas das práticas em curso; é normalmente de natureza experimental, portanto, está mais provavelmente sujeita a testes e taxas razoáveis de falhas; seu processo contempla a revisualização, remodelagem, representação e reformatação imaginativa dos objetos e das práticas cotidianas; é consequência do encorajamento a mudanças via exploração legítima das fronteiras epistêmicas, éticas, disciplinares e de práticas estabelecidas; tem a potencialidade de expandir compreensões e percepções acerca de si mesma e sobre os demais atores envolvidos, permitindo autorrepresentações do passado, do futuro e de possibilidades transcendentes aos limites estritos dos fatos; permite e estimula o desenvolvimento de mundos imaginários e as compreensões acerca de como estes podem impactar sobre os mundos reais e o curso das vidas; sua natureza principal é transdisciplinar, com origem na busca por solução de problemas, sendo descentralizada e associada à produção de conhecimento em contínuo progresso; carrega junto a potencialidade de expandir entendimentos e explorações sobre novas funções e usos possíveis de um objeto; e corresponde à aplicação bem-sucedida de ideias.

Diante disso, fica evidente que inovação disruptiva na educação não pode se limitar à melhoria dos indicadores de eficiência e eficácia produtivistas, mas tem ligação direta com a democratização como possibilidade de mais pessoas participarem dos processos de construção científico-tecnológica e sociocultural. Ainda assim, a inovação educacional disruptiva aqui em argumento, alavancada pelos REA e práticas abertas como os $\mathrm{MOOC} / \mathrm{SOOC}$, não se explica pela via da massificação. Esse tem sido um aspecto amplamente criticado desde que surgiram as atividades 
de educação a distância mais remotas. Crítica bastante combatida, inclusive, com os resultados práticos que conferem aos egressos de cursos a distância lugares de destaque em concursos públicos, conquistas de vagas de emprego de alta concorrência, sucesso profissional (SAEGER e MELO, 2016). As avaliações dos próprios cursistas são satisfatórias quanto aos cursos em andamento ou concluídos, conforme os últimos indicadores de recentes pesquisas sobre as ofertas da Universidade Aberta do Brasil (CAPES/UAB, 2018).

No Brasil, o contexto educacional dos últimos doze anos (2006-2018) é marcado pelo incentivo à expansão do ensino superior via ampliação do acesso e interiorização. No contexto brasileiro, o fato de atingir e incluir um amplo público que nunca imaginava ter acesso ao sistema público de formação universitária já está na seara da inovação educacional disruptiva como democratização do conhecimento. A criação do sistema Universidade Aberta do Brasil (UAB) foi um dos marcos nesse processo. Da mesma forma, as políticas públicas educacionais têm parametrizado competências e metas que incluem diretrizes para formação básica e superior mediada por tecnologias. Destacam-se as estratégias 5.3 e 7.12 na Lei n 13.005 de 25 de junho de 2014 que aprova o Plano Nacional de Educação (PNE) com vigência 2014-2024, as quais explicitam claramente a preferências por softwares livres e REA. Outros marcos são: a Resolução CNE/CES n ${ }^{0}$ 1, de 11 de março de 2016, que determina a disponibilização de cursos de educação superior a distância como REA; a Portaria MEC n 300 de 19 de abril de 2016, que trata de recepção, avaliação e distribuição de recursos educacionais digitais abertos ou gratuitos; o edital do PNLD 2019 que inclui uma cláusula sobre licença aberta para o material complementar. No rumo da consolidação dessas iniciativas, o MEC criou em agosto de 2017 um Grupo de Trabalho (GT) sobre REA que visa discutir o formato, a participação e os objetivos pretendidos na criação de políticas institucionais ${ }^{2}$.

2 Cf. <http://aberta.org.br/mec-cria-grupo-de-trabalho-gt-sobre-rea/>. 
Nessa expansão cultural do acesso à Internet e novas mídias, as próprias agências de fomento como a CAPES incentivam a publicação, compartilhamento e disseminação de materiais educacionais produzidos nos cursos ofertados no âmbito do Sistema UAB. Em 14 de julho de 2016 foi publicada a Portaria n 106 que "Institui o Portal eduCAPES, portal de objetos educacionais abertos com acesso livre, público e gratuito do Sistema Universidade Aberta do Brasil - UAB e parceiros". Essa política nacional considera a relevância do atendimento das metas estabelecidas no PNE, com destaque para as metas 12, 14, 15 e 16. Assim, tendo em vista a prática das cinco liberdades dos REA (reter, reutilizar, readaptar, remixar e redistribuir) é possível compreender que sustentam a premissa fundamental da inovação educacional disruptiva, que é a acessibilidade com os desdobramentos inclusivos que são as remodelizações, reformatações, remixagens, coproduções e redistribuições. Segundo o projeto Opening Educational Practices in Scotland (OEPS), educação aberta é de livre acesso, promove reutilização, implica transparência e pode ser compartilhada ${ }^{3}$. Na definição de Práticas Educacionais Abertas (PEA), a equipe do projeto OEPS destaca a promoção da equidade, justiça social e as oportunidades para todos aqueles que, por algum motivo, estão afastados da educação regular ${ }^{4}$.

Conforme Christensen, Raynor e McDonald (2015) a inovação disruptiva é processual e não se concentra numa ideia, serviço, projeto ou produto de modo isolado. Inovação disruptiva não está relacionada a pequenas melhorias ou modificações, mas trata-se de propostas que podem atingir públicos nunca incluídos e isso não implica necessariamente altos custos ou está atrelado às esferas privadas. Os autores destacam pelo menos três características e aspectos importantes da inovação disruptiva que podem ser aplicados a uma análise no campo educacional: a) processual; b) modelos de trabalho diferentes daqueles tradicionalmente conhecidos; c) algumas inovações são bem-sucedidas outras não. Desse modo,

\footnotetext{
3 Cf. <https://oepscotland.org/>.

4 Cf. <https://oepscotland.org/about/definitions/>.
} 
Inovação, em geral, pode ser assumida como o fruto decorrente da utilização do novo conhecimento nas organizações, com sucesso reconhecido, de tal maneira que as ideias associadas com inovação estejam formalmente organizadas, gerenciadas, realizadas e, efetivamente, impactando na prática [...] hoje a inovação é assumida como algo diretamente associado à possibilidade de um desenvolvimento econômico e social sustentável (MOTA; SCOTT, 2014, p. 19).

Nesse sentido, MOOC/SOOC e REA são estrategicamente potentes para gerar inovação educacional disruptiva. Tanto os modelos de cursos quanto os formatos são flexíveis o suficiente para democratizar o acesso ao conhecimento por meio de processos educacionais culturalmente e economicamente livres, autônomos, interativos e ubíquos como nunca imaginados, mesmo com a ascensão da Internet. O incremento de portais públicos, repositórios e referatórios que fomentem práticas educacionais livres e abertas, tanto do ponto de vista legal quanto técnico, pode ampliar ainda mais esse novo modelo educacional virtual que incentiva pessoas a estudar, criar, produzir, compartilhar conhecimentos de várias áreas de interesse. Enquanto os modelos mais tradicionais de educação online e a distância investem para atingir públicos e concentram a oferta em cursos que se enquadram em modelos curriculares regulares, os MOOC/SOOC e REA fazem emergir uma cultura de autoria e coautoria como atos éticos e estéticos, responsáveis e responsivos. Ou seja, não se limitam apenas à educação formal, aos currículos e projetos didáticos que passam pelas métricas de supervisão e regulação dos ministérios e instâncias governamentais.

(Re)cursos livres e abertos: inovação disruptiva na prática das cinco liberdades

Segundo Nóvoa e Amante (2015) "hoje, como sempre, é na busca da liberdade que se define o sentido de uma pedagogia universitária, 
que não é mera técnica" (p. 23). No contexto das plataformas Web 2.0 e superiores (BRUNS, 2008; BONK, 2009), do ponto de vista do pensamento aberto como democratização da inovação (VON HIPPEL, 2005), as informações podem sofrer adaptações, reformulações, remixagens, complementações e melhorias por variados autores que se tornam coautores em rede (AMIEL, 2012). As tecnologias contemporâneas têm tornado possível que a produção seja compartilhada e parametrizada pela abertura do código fonte, disponibilização de arquivos em formatos editáveis, standarização, participação ubíqua, usabilidade, acessibilidade.

Segundo Pestana e Cardoso (2017), recursos educacionais podem ser produzidos e divulgados em arquivos ou páginas online como as wikis, por exemplo, de modo aberto permitindo adaptações e reformulações diante de especificidades contextuais, curriculares, infraestrutura e público-alvo. Butcher, Kanwar e Uvalic-Trumbic' (2011) explicam que REA são materiais em qualquer suporte ou mídia que estão sob domínio público ou estão licenciados de maneira aberta para que possam ser utilizados e/ou adaptados. Para incrementar a inovação disruptiva é imprescindível desenvolver projetos de criação e gestão compartilhada de conhecimento mediada por tecnologias em rede com plataformas abertas como a Wiki independente das áreas de conhecimento (MEDEIROS, 2017).

Nessa linha de trabalho e pesquisa, as versões digitais são mais propensas ao remix e atualização de conteúdos, o que torna possível a prática da educação aberta. Um dos potenciais dos REA reside na sua agregação aos princípios e condições operacionais da hipermídia preconizados pelos movimentos contemporâneos da renovação metodológica e inovação inspirada em recursos e ferramentas de informação e comunicação eletrônica. As inovações metodológicas, conhecimentos técnicos e práticos realçam a necessidade de revisão epistemológica, especialmente no campo dos valores e concepções (contraponto entre cultura proprietária e livre/aberta). A aposta é que os atos ético e estético na integração das tecnologias em rede da Web 2.0 na educação possam gerar, à curto ou médio prazo, atualização curricular, uma vez que o potencial de transformação dos REA está no compartilhamento e atualização constante em 
rede. Os atos ético e estético são basilares na produção colaborativa de REA na Web 2.0, tendo em vista que o ato é ação concreta, responsável, que, ao mesmo tempo, responde algo. O ato é o agir humano como ação transformadora (BAKHTIN, 2010; JACQUES, 2017). Open Educational Resources (OER) ou, na língua portuguesa Recursos Educacionais Abertos (REA) são, segundo definições da UNESCO e Commonwealth of Learning, materiais de ensino, aprendizado e pesquisa em qualquer suporte ou mídia. São de domínio público ou licenciados de maneira aberta, permitindo livre acesso, reutilização, adaptação com redistribuição (UNESCO, 2012, p. 1). REA implicam "ciclos virtuosos" com verdadeiros efeitos transformadores (WINDLE et al., 2010). Os conteúdos publicados na Internet requerem critérios de seleção (BRUNS, 2008; BONK, 2009), modelizações e gestão apropriada para que sua reutilização seja cada vez mais incentivada sempre sob os pilares dos princípios éticos. Os processos de publicação, distribuição e divulgação com ferramentas de pesquisa precisam ser ampliados e atualizados. "Nessa linha de argumentação, o desafio contemporâneo da educação aberta coloca a necessidade de desenvolver bases de gestão de projetos como reflexão sobre a didática de e-learning" (MALLMANN; NOBRE, 2017, p. 10).

Conforme o portal Educação Aberta5 "recursos podem ser considerados 'abertos' com base em dois princípios: 1) abertura legal, com o uso de licenças mais permissivas (como Creative Commons) e 2) abertura técnica, através de formatos e protocolos abertos ou especificados abertamente". O Open Education Group, formado por David Wiley, Lane Fischer e John Hilton III ${ }^{6}$, explica que o termo conteúdo aberto, descreve qualquer (software é descrito por outros termos como open source) obra intelectual licenciada de uma maneira que fornece permissão livre e perpétua para exercer atividades baseadas nos cinco direitos (5R): Reter — o direito de fazer e guardar cópias próprias do conteúdo (por exemplo, download, duplicar, armazenar e gerenciar); Reutilizar - o direito de usar o conteúdo de várias

5 Cf. <http://educacaoaberta.org/rea/>.

6 Cf. <www.opencontent.org $>$. 
formas (por exemplo, em uma classe, em um grupo de estudo, em um site, em um vídeo); Rever — o direito de adaptar, ajustar, modificar ou alterar o conteúdo em si (por exemplo, traduzir o conteúdo para outro idioma); Remix - o direito de combinar o conteúdo original ou revisado com outro conteúdo aberto para criar algo novo (por exemplo, incorporar o conteúdo em criações personalizadas); Redistribuir — o direito de compartilhar cópias do conteúdo original, suas revisões, ou seus remixes com os outros (por exemplo, dar uma cópia do conteúdo a um amigo).

O compartilhamento público dos REA é regido pelo princípio colaborativo e, inclusive, o de economicidade. Integra os argumentos centrais enfatizados pela filosofia software livre e o conceito objetos de aprendizagem. REA são materiais didáticos, objetos como vídeos ou arquivos de som, imagens, livros, artigos, trabalhos de conclusão de curso. Weller (2010), considera que os REA oriundos de projetos institucionais são os "big OER" sendo que produções abertas individualizadas baseadas nas ferramentas da Web 2.0 em menores escalas podem ser chamadas de "little OER". Para isso, os autores e coautores precisam optar pelo tipo de licenciamento, que varia entre (re)utilização, revisão, remixagem e redistribuição que alternam entre opções de licenças mais permissivas ou não.

Com base nas opções disponíveis nas ferramentas disponibilizadas pelo Creative Commons (CC), existe uma cartografia de pelo menos seis relações a serem geradas a partir da combinação entre os itens obrigatórios (BY) e opcionais gerando licenciamentos mais permissivos ou mais restritivos do ponto de vista da abertura. Além do Domínio Público (CC0 ou CCØ), em todos os casos a opção BY-Atribuição de autoria fica ativada, ou seja, o pensamento aberto em relação aos recursos educacionais está modelado na perspectiva do compartilhamento e da identificação/referência de autoria. Share Alike (SA) refere-se ao compartilhamento da mesma perspectiva de licenciamento mantendo ativos os "ciclos virtuosos". As atribuições NoDerivs (ND) e NonCommercial (NC) geram possibilidades mais restritivas para futuras cocriações e explorações com fins lucrativos. Segundo as instruções da University British Columbia (UBC), não existe 
uma licença mais adequada ou menos adequada, mesmo quando se trata de atribuições ND. Isso depende não somente do tipo de reutilização, mas das especificidades da situação e das intencionalidades em questão ${ }^{7}$. Pesquisadores, professores, estudantes e qualquer pessoa interessada em aprender pode reutilizar os recursos para fins de ensino, aprendizagem, pesquisa e/ou extensão sem precisar solicitar qualquer tipo de autorização ao autor original. Já quando se trata de recursos com licença fechada (Copyright), sua utilização torna-se restrita e limitada.

Portanto, REA são muito mais do que artefatos digitais para difusão e transferência do conhecimento, pois incentivam a problematização das práticas ilegais de fotocópias, downloads e reutilização sem permissão quando há Copyright. REA sustentam, com base nas cinco liberdades, o movimento das práticas educacionais abertas (HOLMBERG et al. 2011) e, por isso mesmo, conectam-se de diversos modos ao serem reorganizados em cursos nos formatos MOOC/ SOOC. Os princípios da prática da abertura, liberdade e flexibilidade dos REA permitem questionar os padrões fechados de produção, publicação e livre acesso aos recursos digitais. Nesse contexto, licenciar recursos para reutilização, adaptação, reorganização, reformatação e novos compartilhamentos significa maior divulgação da produção e da própria autoria e, mais importante do que isso, a abertura para coautoria. Nenhuma licença Creative Commons rompe com o princípio da referência e da citação clara do autor e dos coautores da obra original. O licenciamento flexível e claramente identificado no recurso tem sido indicado pelos estudiosos do assunto como o principal aspecto a ser considerado para classificar qualquer recurso digital como aberto ou fechado (HENRIQUES, 2017). Nem sempre a diferença entre Copyright (todos os direitos reservados) e licenciamento aberto é bem compreendida. Qualquer artefato com Copyright exige que previamente à reutilização seja realizada solicitação ao detentor dos direitos. Por isso, no prisma jurídico, fazer cópias e modificar materiais com

7 Cf. <http://wiki.ubc.ca/Copyright:Support_Guides/Creative_Commons_Guide/Creative_Commons_FAQs>. 
Copyright sem autorização é considerado um ato ilegal. Nessa linha, há ainda outros problemas como a pirataria e os plágios em relação a patentes e obras protegidas contra derivações. Por isso, é emergente que os atos ético e estéticos sejam geradores de inovação disruptiva em termos dos impactos para promoção da cultura digital de expansão da educação aberta e democratização do acesso ao ensino superior.

\section{Design-Based Research (DBR): inovação educacional disruptiva com SOOC e REA}

Design-Based Research (DBR) adota procedimentos cíclicos de delimitação de problemas práticos com vistas à criação de soluções, implementação, avaliação e redesign dos produtos gerados (WANG e HANNAFIN, 2005). Uma característica fundamental é o compartilhamento das etapas do processo entre todos os envolvidos sendo especialmente eficaz em contextos coletivos e responsivos (Design-Based Research Collective, 2003). Do mesmo modo, tem um caráter intervencionista e pragmático porque as soluções projetadas são aplicadas visando mudanças na prática. Inovação disruptiva na universidade pode se apoiar na DBR porque essa é uma tipologia de pesquisa que permite implementar as soluções, avaliá-las em ação para seu refinamento. Uma única aplicação ou um trabalho individual, isolado, tem pouco valor para construção de evidências sustentáveis. "O intercâmbio de conhecimentos e práticas entre os participantes, o pluralismo metodológico e teórico e a ação intervencionista possibilitam inovação no desenvolvimento" (MAZZARDO et al., 2016, p. 957). Como resultados científico-tecnológicos, essenciais para o movimento inovador disruptivo, os processos de pesquisa educacional, orientados pelos princípios metodológicos da $\mathrm{DBR}$, geram tanto produtos quando novos conhecimentos sobre os processos. Planejar, implementar, avaliar e redesenhar cursos no formato SOOC e REA em universidade, pautados pela DBR, gera inovação educacional disruptiva porque 
onde inovação é o tema central, as universidades são simultaneamente centros geradores de inovação, essencialmente motivados por demandas externas, e repositórios do conhecimento em nossa sociedade. Assim, a maneira com que o conhecimento é desenvolvido, disseminado e aplicado afeta não só a riqueza cultural de uma sociedade, mas também impacta em sua competitividade regional e global (MOTA e SCOTT, 2014, p. 30).

Desenvolver SOOC na universidade orientada pela DBR é um processo de pesquisa cuja natureza é aplicada, de objetivos não apenas descritivos, mas exploratórios e explicativos, implicando o foco em objetos que não se limitam aos procedimentos da pesquisa laboratorial ou bibliográfica, mas essencialmente de campo. Mota e Scott (2014, p. 59) afirmam que "os MOOCs têm sido considerados por alguns estudiosos na área o experimento mais importante dos últimos tempos na educação superior e pode representar um ponto de inflexão para abordagens de ensino e aprendizagem usando a internet". Nesse cenário disruptivo, desenvolveu-se o "SOOC: autoria colaborativa em rede" na Universidade Federal de Santa Maria. O curso esteve vinculado ao Núcleo de Tecnologia Educacional (NTE) responsável pela proposta e implementação de cursos de capacitação ligados ao sistema UAB, ocorreu ao longo de cinco semanas e teve cinquenta vagas. Todos os conteúdos foram organizados sob licenciamento Creative Commons distribuídos em três módulos (Figura 1). Todos os conteúdos foram produzidos pelos professores-pesquisadores contemplando diversos formatos como páginas hipermidiáticas, ebook, arquivos $\mathrm{PDF}$, links externos para páginas avulsas, sites ou repositórios, links para coleções de páginas em plataformas wiki. Cada módulo teve um Fórum destinado para dúvidas. $\mathrm{Na}$ primeira semana foram postadas a apresentação/expectativas, seguido de um fórum de análises e reflexões a respeito dos principais desafios, avanços e fundamentos da autoria colaborativa em rede. Foram realizadas duas sessões síncronas em datas e horários diversificados com a disponibilização posterior do conteúdo gravado em vídeo. 
Figura 1 - Recursos e atividades dos módulos do SOOC

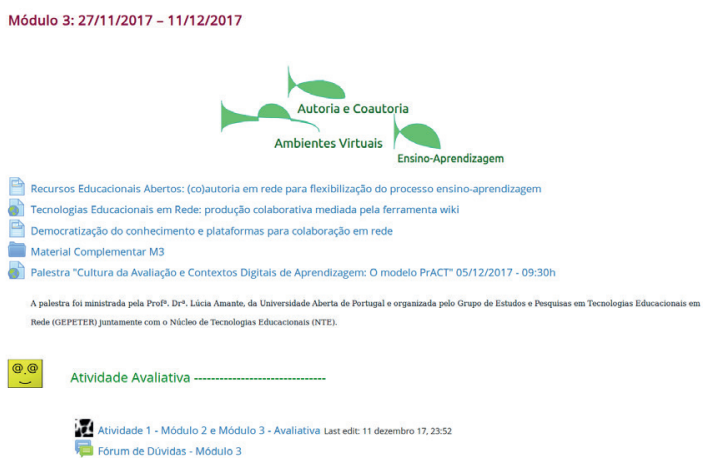

Módulo 2: 13/11/2017 - 27/11/2017

Módulo 1: 06/11/2017 - 13/11/2017
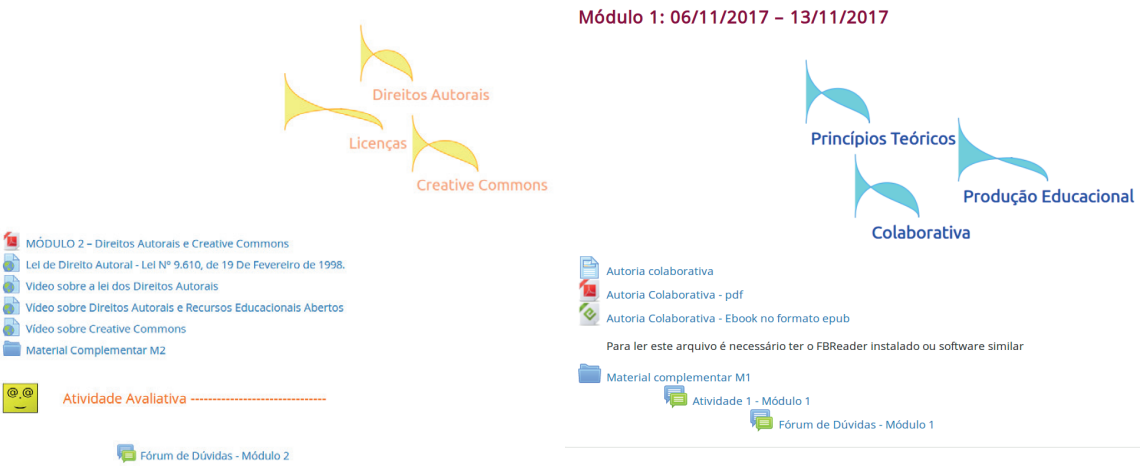

Fonte: Screenshot, Moodle NTE/UFSM-2017.

A atividade avaliativa do curso foi realizada ao longo de 4 semanas na ferramenta de atividade Wiki dentro da plataforma Moodle (Figura 2). A produção dos participantes gerou 12 páginas de conteúdo hipermidiático com 19.074 palavras adicionadas. No lastro da inovação educacional disruptiva, a prática das cinco liberdades exigiu habilidades contemporâneas, trânsito pelos conceitos fundamentais e capacidades intelectuais (KAFAI, et al., 1999) para o (re)uso, revisão, remixagem e redistribuição de REA. 
Figura 2 - Produção colaborativa em rede organizada pelos participantes

\begin{tabular}{|l|l|}
\cline { 2 - 2 } Alfabético & Estr \\
\hline Página inicial & \\
\hline Palavras: 1270 \\
Última alteração: segunda, 11 Dez 2017, 23:48
\end{tabular}

Construção de novos saberes: discutindo a teoria e a produção de conhecimento de modo colaborativo em rede

Palavras: 426

Última alteração: domingo, 10 Dez 2017, 15:59

\section{Desafios e avanços}

Palavras: 2208

Última alteração: segunda, 11 Dez 2017, 18:12

Direitos Autorais

Palavras: 1019

Última alteração: segunda, 11 Dez 2017, 23:50

\section{Licenças Flexíveis na Internet}

Palavras: 856

Última alteração: segunda, 11 Dez 2017, 18:14

\section{materiais didáticos produzidos pelo NTE/UFSM}

Palavras: 229

Última alteração: segunda, 11 Dez 2017, 18:00

\section{Plataformas e ferramentas de suporte à autoria colaborativa em rede}

Palavras: 2666

Última alteração: segunda, 11 Dez 2017, 23:52

\section{Principais características de autoria colaborativa em rede}

Palavras: 684

Última alteração: segunda, 11 Dez 2017, 18:10

\section{Recursos educacionais Abertos - REA}

Palavras: 1678

Última altearação: segunda, 11 Dez 2017, 20:16

\section{Referências}

Palavras: 106

Última alteração: segunda, 11 Dez 2017, 15:40

Páginas sem links

Desafios e avanços (tecnológicos, científicos, sociais, culturais, econômicos, linguísticos, éticos, jurídicos

Palavras: 729

Última alteração: domingo, 10 Dez 2017, 15:58

mudanças nos modelos de autoria

Palavras: 340

Última alteração: domingo, 10 Dez 2017,15:58

Fonte: Screenshot, Moodle NTE/UFSM-2017. 
Nesse viés, a sustentabilidade da inovação educacional disruptiva está acoplada ao desenvolvimento e aprimoramento constante da Fluência Tecnológico-Pedagógica (FTP) de todos os coparticipes. Assim, a FTP é chave para o trânsito pelas competências explicitadas no Open Educational Resources (OER) Competency Framework (Figura 3). Aprimorar FTP para se familiarizar com os REA (D1), pesquisar (D2), utilizar (D3), criar (D4) e compartilhar (D5) REA. A FTP é o que pode tornar as pessoas mais capacitadas para reutilizar e compartilhar REA. Windle e outros (2010) concluem que as comunidades e o empowerment são fundamentais. Para eles, "as evidências sugerem que aqueles que se sentem capacitados para reutilizar são mais propensos a compartilhar e vice-versa" (p. 14). Isso impulsiona inovação educacional disruptiva com atos éticos e estéticos em redes nas situações de aprendizagem, interação, produção e compartilhamento livre e aberto de conhecimento tanto no plano formal quanto nas comunidades informais ou grupos corporativos de aprendizagem.

Figura 3 - Open Educational Resources (OER) Competency Framework

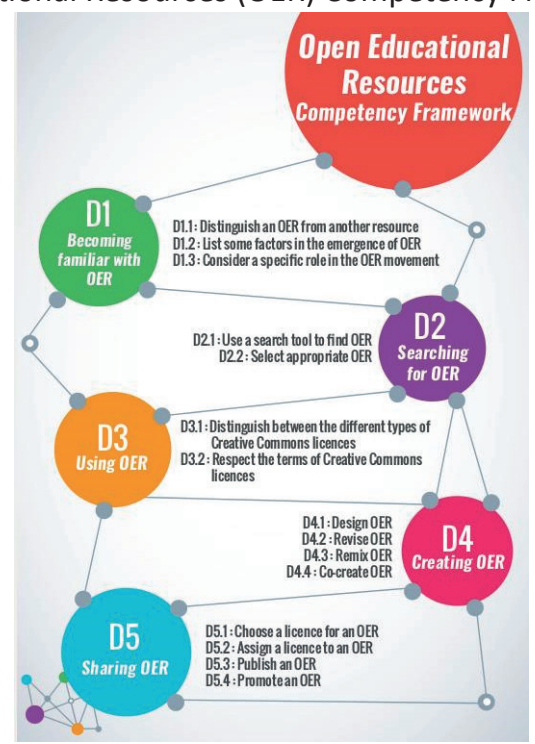

Fonte: International Organisation of La Francophonie (IOF) - 2016. 
Isso que aqui se nomeia FTP está inscrito no amplo universo dos conhecimentos, habilidades e conceitos da vida em rede mediada por tecnologias. Todas as pulsações, tensões e tensionamentos da interatividade hipermidiática englobam níveis micro, meso e macro de ordem econômica, social, cultural com todos os mecanismos de exposição, comunicação, socialização, consumo, vigilância, persuasão e poder envolvidos. Haverá condições para avançar e consolidar resultados de inovação educacional disruptiva se houver investimento concreto na FTP.

\section{Considerações finais}

Em análise pormenor, o SOOC organizado com REA teve como foco o estudo dos fundamentos e práticas da autoria colaborativa em rede sendo potente para gerar inovação educacional disruptiva na universidade. Destacam-se as principais características:

- intencionalmente organizado para flexibilizar os tradicionais processos de capacitação na universidade. Assim, explorou-se uma possibilidade alternativa de prática online e aberta;

- de natureza experimental, pois tratou-se de primeira atividade de capacitação ofertada nesse formato, exigindo atenção e cuidado diante da probabilidade de falhas de conexão, funcionamento das atividades, prazos, suporte técnico, orientações, tutorias, etc.;

- recursos e atividades disponíveis com licenças Creative Commons. Podem ser reutilizados, reformulados e recompartilhados. O movimento realizado possibilitou aprimorar as competências indicadas pelo OER Competency Framework. O foco éa transformação das práticas cotidianas;

- a equipe responsável pesquisa e tem experiências práticas em educação aberta e online;

- tornou-se uma forma para encorajar o aprimoramento de Fluência Tecnológico-Pedagógica (FTP) como ampliação de mudanças para além das fronteiras epistêmicas, éticas, disciplinares e de práticas já estabelecidas na instituição; 
- possibilitou expandir compreensões e percepções dos participantes acerca de si mesmos e sobre os demais atores envolvidos, permitindo análise retrospectiva e prospeç̧ões sobre FTP, direitos autorais, segurança na Internet, plataformas colaborativas, materiais didáticos;

- permitiu compreensões acerca de como as decisões e práticas cotidianas mediadas pelas tecnologias em rede no contexto da Web 2.0 impactam o curso das vidas;

- sua natureza organizativa e participativa foi transdisciplinar com foco na solução de problemas específicos de contextos reais da reutilização, produção e compartilhamento de recursos educacionais na universidade com atenção aos direitos autorais e REA;

- expandiu entendimentos e explorações sobre novos desafios profissionais no contexto contemporâneo mediado pelas tecnologias em rede; $\mathrm{e}$

- corresponde a um processo orientado por $D B R$ cuja ideia foi bem-sucedida tendo em vista os indicadores de participação, a dinâmica de escrita colaborativa, os produtos criados e as manifestações de satisfação dos participantes. Os resultados podem sustentar o redesign com novos ciclos iterativos.

Incentivar a inovação educacional disruptiva, por meio da integração das ferramentas Web 2.0 com conteúdo aberto, requer conhecimento e apropriação de formas de ensinar/aprender em rede, flexibilizando e diversificando o processo com opções de recursos e atividades educacionais. Isso é central para o suporte da comunicação bidirecional em torno dos conteúdos curriculares como prática das cinco liberdades dos REA. Configura, pois, atos ético e estético enquanto responsabilidade criativa para inovação disruptiva e desenvolvimento científico-tecnológico. Do mesmo modo, o incentivo e fomento com iniciativas e políticas públicas em larga escala requer adesão das instituições de ensino superior em todo país com programas institucionais voltados para gestão escolar democrática e processos de capacitação constantes.

Produzir conhecimento educacional sobre as implicações dos atos ético e estético nas práticas inovadoras disruptivas, mediadas por REA e 
$\mathrm{MOOC/SOOC} \mathrm{exige} \mathrm{reflexão} \mathrm{sobre} \mathrm{modelos} \mathrm{pedagógicos} \mathrm{blended,} \mathrm{online,} \mathrm{free,}$ open, massive visto que os processos de interação são cada vez subsidiados pela mediação tecnológica no contexto da Web 2.0. Portanto, Massive/Small Open Online Courses (MOOC/SOOC) e Recursos Educacionais Abertos (REA) são potentes para gerar inovação disruptiva na educação online e aberta na medida em que: a) são centrados em modelos flexíveis e permissivos pautados em materiais com alto poder interativo; b) a autoria é acentuadamente colaborativa; c) os materiais produzidos são maciçamente de caráter livre e aberto para reter cópias, reutilização, revisão, remixagem, redistribuição; d) o potencial hipermidiático (interação e interatividade) dos ambientes, plataformas e repositórios virtuais é altamente explorado; e) aumenta a FTP para compreender tudo que é possível criar e compartilhar em rede.

\section{Referencias}

AMIEL, T. Educação aberta: configurando ambientes, práticas e recursos educacionais. In: SANTANA; B.; ROSSINI, C.; PRETTO, N. (Org.). Recursos Educacionais Abertos: práticas colaborativas políticas públicas. 1. ed. Salvador: Edufba/São Paulo: Casa da Cultura Digital, 2012.

CHRISTENSEN, C. M.; RAYNOR, M.; McDONALD, R. What Is Disruptive Innovation? In: Harvard Business Review. Dezembro de 2015. Disponível em: <https://hbr.org/2015/12/what-is-disruptive-innovation>. Acesso em: 15 jan. 2018.

ARAYA, E.; VIDOTTI, S. Criação, proteção e uso legal de informações em ambientes da World Wide Web [online]. São Paulo: Editora UNESP; São Paulo: Cultura Acadêmica, 2010. Disponível em: <http:books.scielo.org >. Acesso em: 15 jan. 2018.

BAKHTIN, M. Para uma filosofia do ato responsável. Trad. Valdemir Miotello e Carlos Alberto Faraco. São Carlos: Pedro \& João Editores, 2010.

BONK, C. J. The world is open: how web technology is revolutionizing education. San Francisco: Jossey-Bass, 2009. 
BUTCHER, N.; KANWAR, A.; UVALIC-TRUMBIC', S. A Basic Guide to Open Educational Resources (OER). Commonwealth of Learning: Vancouver, 2011.

BRUNS, A. Blogs, Wikipedia, Second Life and Beyond: from production to produsage. New York: Peter Lang Publishing, 2008.

CAPES. Boletim Informativo dos Resultados da Pesquisa com Estudantes do Sistema UAB. Brasília, janeiro de 2018. Disponível em: <http://www.capes.gov.br/uab/resultados-da-pesquisa-com-os-estudantes-do-sistema-uab〉. Acesso em: 15 jan. 2018.

CASTELLS, M. A Galáxia da Internet: Reflexões sobre a Internet, os Negócios e a Sociedade. Trad. Maria Luiza X. de A. Borges. Rio de Janeiro: Zahar, 2003.

DESIGN-BASED RESEARCH COLLECTIVE. Design-Based Research: An Emerging Paradigm for Educational Inquiry. 2003 Disponível em: <http://www.designbasedresearch.org/reppubs/DBRC2003.pdf >. Acesso em 15 jan. 2018.

JACQUES, J. S. Performance docente na (co)autoria de Recursos Educacionais Abertos (REA) no ensino superior: atos éticos e estéticos. Tese (Doutorado em Educação) Santa Maria: PPGE/UFSM, 2017.

FREEMAN, R. Creating learning materials for open and distance learning: a handbook for authors and instructional designers. Commonwealth of Learning: Canadá, 2005.

HENRIQUES, J. Catálogo de características para análise e avaliação de Recursos Educacionais Abertos (REA): ferramenta de avaliação no formato checklist. Dissertação (Mestrado em Pedagogia do eLearning (MPel)) - Universidade Aberta de Portugal, Lisboa, 2017.

HOLMBERG, C. et al. Beyond OER: Shifting Focus from Resources to Practices. The OPAL Report 2011. International Council for Open and Distance Education (ICDE)/UNESCO, 2011.

INTERNATIONAL ORGANISATION OF LA FRANCOPHONIE (IOF). Open Educational Resources (OER) Competency Framework. Setembro de 2016. Disponível em: <https://www. ifadem.org/sites/default/files/divers/livret-rel-eng-web_0.pdf>. Acesso em:15 jan. 2018. 
KAFAI, Y., et al. Being Fluent with Information Technology. 1999. Disponivel em: <http://www.nap.edu/catalog/6482.html〉. Acesso em 15 jan. 2018.

MALLMANN, E. M. e NOBRE, A. M. F. An open channel in higher education? MOOC and OER in the digital world. Apertura: Revista de Innovación Educativa, v. 9, n. 2, 2017. Disponível em: <http://www.udgvirtual.udg.mx/apertura/index. php>. Acesso em: 15 jan. 2018.

MAZZARDO, M., et al. Design-Based Research: desafios nos contextos escolares. Atas CIAIQ2016 5o Congresso Ibero-americano de Investigação Qualitativa em Educação. v. 1, Braga: 2016.

MEDEIROS, M. F. Wikipampa: suporte à gestão do conhecimento no sistema de bibliotecas da Universidade Federal Do Pampa. Dissertação (Mestrado em Tecnologias Educacionais em Rede?) - Santa Maria, PPGTer/UFSM, 2017.

MOTA, R. e SCOTT, D. Educando para inovação e aprendizagem independente. 1. ed. - Rio de Janeiro: Elsevier, 2014.

NÓVOA, A. S.; AMANTE, L. Em busca da Liberdade. A pedagogia universitária do nosso tempo. Revista de Docência Universitária (REDU). v. 13, n. 1, p. 21-34, ene./abr. 2015.

O'REILLY, T. What is Web 2.0. Design patterns and Business models for the next generation of software. 2005. Disponível em: <http://www.oreilly.com/pub/a/ web2/archive/what-is-web-20.html $>$. Acesso em: 15 jan. 2018.

PESTANA, F.; CARDOSO, T. Integração curricular da Wikipédia no ensino básico: uma proposta de formação de professores. Educação, Formação \& Tecnologias, v. 10, n. 1, p. 20-35, jan./jun. 2017. Disponível em: <http://eft.educom.pt/index. php/eft/article/viewFile/556/263>. Acesso em: 15 jan. 2018.

SAEGER, M. T.; MELO, A. H. A. Inserção do Egresso de Cursos a Distância no Mercado de Trabalho: um Estudo Voltado para a Licenciatura em Matemática. Revista EaD em Foco. Rio de Janeiro, v .6 n. 2, 2016.

TAPSCOTT, D.; WILLIAMS, A. D. Wikinomics: Como a Colaboração em Massa pode mudar o seu Negócio. Trad. Marcello Lino. Rio de Janeiro: Nova Fronteira, 2007. 
UNESCO. Declaração REA de Paris. In: Congresso Mundial Sobre Recursos Educacionais Abertos, Paris: Unesco, 2012. Disponível em: <http://www. unesco.org/new/fileadmin/MULTIMEDIA/HQ/CI/WPFD2009/Portuguese_ Declaration.html>. Acesso em 15 Jan. 2018.

ZANIN, A. A. Recursos educacionais abertos e direitos autorais: análise de sítios educacionais brasileiros. Rev. Bras. Educ., Rio de Janeiro, v. 22, n. 71, e227174, 2017. Disponível em <http://www.scielo.br/scielo.php?script=sci_arttext\&pid=S1413-24782017000400230\&lng=en\&nrm=iso >. Acesso em: 15 jan. 2018.

VON HIPPEL, E. Democratizing Innovation. Massachusetts: The MIT Press, 2005. WANG, F. e HANNAFIN, M. J. Design-Based Research and Technology-Enhanced Learning Environments. Educational Technology Research and Development, v. 53, n. 4, p. 5-23, 2005. Disponível em: <https://link.springer.com/article/10.1007/ BF02504682>. Acesso em: 15 jan. 2018.

WELLER, M. Big and little OER. In: OpenED2010: Seventh Annual Open Education Conference, 2-4 de novembro, Barcelona, 2010. Disponível em: <http://oro.open. ac.uk/24702/2/926FFABC.pdf> Acesso em: 15 jan. 2018.

WINDLE, R. J. et al., Sharing and reuse in OER: experiences gained from open reusable learning objects in health. Journal of Interactive Media in Education, n. 1, 2010. Disponivel em: <https://jime.open.ac.uk/articles/10.5334/2010-4/>. Acesso em: 15 jan. 2018.

Recebido: 12/02/2018

Received: 02/12/2018

Recibido: 12/02/2018

Aprovado: 06/03/2018 Approved: 03/06/2018 Aprobado: 06/03/2018 